\title{
O legado político de Joseph Smith Jr., o fundador da igreja Mórmon
}

\section{The political legacy of Joseph Smith Jr., founder of the Mormon Church}

Douglas de Castro*

Resumo: Joseph Smith Jr. foi o fundador e profeta de A Igreja de Jesus Cristo dos Santos dos Últimos Dias nos Estados Unidos, também conhecida como a igreja mórmon. Ele também foi o primeiro candidato a presidente dos Estados Unidos a ser assassinado. Em um país em que a liberdade religiosa fez parte da formação da identidade compartilhada pelos imigrantes europeus e que em 1789 passou a integrar sua Constituição, os episódios de perseguição e exílio a que foram submetidos os membros da igreja mórmon apontam para a causa próxima do engajamento político de seu líder religioso. Desse modo, o presente trabalho tem por finalidade imediata analisar o processo de formação do pensamento político de Joseph Smith Jr., traçando os principais eventos envolvendo sua participação como profeta e os membros da igreja mórmon para garantir sua segurança e liberdade de crença e religiáo. Os marcos temporais do trabalho abrangem a fundação da igreja mórmon em 1830 e o assassinato de Joseph Smith Jr. na cadeia de Carthage, Illinois em 1844. Como finalidade mediata, pretende contribuir para o conhecimento nas áreas da ciência política e direito de um tema desconhecido nos círculos acadêmicos. Para alcançar este objetivo de pesquisa, adotaremos o caminho metodológico qualitativo de abordagem indutiva e utilização de process-tracing, objetivando traçar as condiçôes necessárias e suficientes para que Joseph Smith Jr. formasse seu pensamento político enquanto líder religioso e profeta e que decidisse concorrer à presidência dos Estados Unidos para proteger a igreja e seus membros da perseguição política e religiosa.

Palavras-chave: Política. Liberdade religiosa. Direito. Joseph Smith Jr. Igreja Mórmon.

Abstract: Joseph Smith Jr. was the founder and prophet of The Church of Jesus Christ of Latter-day Saints in the United States, also known as the Mormon Church. He was also the first US presidential candidate to be assassinated. In a country where religious freedom was part of the identity formation shared by European immigrants and which in 1789 became part of its Constitution, the episodes of persecution and exile to which members of the Mormon Church were subjected points to the proximate cause of the political engagement of its religious leader. The immediate purpose of this paper is to analyze the formation process of the Joseph Smith Jr.'s political thought, outlining major events involving his participation as a prophet and members of the Mormon Church to ensure their safety and freedom of belief and religion. The mediate purpose is to contribute to the knowledge in the areas of Political Science and Law of a theme unknown in academia. The temporal framework for this paper is the foundation of the Mormon Church in 1830 and the murder of Joseph Smith Jr. in the Carthage Jail, Illinois, in 1844. To achieve this research objective, we will adopt the qualitative inductive methodological approach and process-tracing, which aims to outline the necessary and sufficient conditions for Joseph Smith Jr. to form his political thought as a religious leader and prophet and to decide to compete to the presidency of the United States to protect the Church and its members from political and religious persecution.

Keywords: Politics. Religious freedom. Law. Joseph Smith Jr. Mormon Church.

* Professor Visitante da FLIA (Estados Unidos). Professor de direito internacional e relaçóes internacionais da UNIP. Bolsista PNPD/CNPQ. Doutor em ciência política (USP). Contato: douggcastro@gmail.com 


\section{Introduçáo}

A Emenda Constitucional $N^{\circ} 1$ da Constituição dos Estados Unidos estabelece que:

O Congresso não fará nenhuma lei respeitando um estabelecimento de religião ou proibindo o seu livre exercício; ou abreviar a liberdade de expressão ou de imprensa; ou o direito do povo de se reunir pacificamente, e de pedir ao governo uma reparaçáo (tradução nossa).

Embora a própria Constituição expressamente tenha previsto a liberdade religiosa no país, a construção dos limites de aplicabilidade da cláusula possuía três desafios principais: o primeiro é geográfico, tendo em vista que o território dos Estados Unidos na época de formação da Constituição limitava-se à Costa Leste, sendo que a maior parte do território Norte-Americano como conhecemos atualmente era território indígena; em segundo lugar, os poderes da Uniáo sobre os estados federados ainda não eram unânimes, havendo muitas objeçóes ao seu exercício; e em terceiro lugar, o fato de que o sistema jurídico adotado fora o de common law, ainda não haviam sido desenvolvidos precedentes pela Suprema Corte em relaçáo aos limites de aplicaçáo da Primeira Emenda (Burnham, 2011).

Desse modo, as religióes tradicionais, cujas crenças e práticas eram conhecidas pelos colonizadores europeus, se refletiam nas colônias americanas, sendo consideradas as causas próximas da Revolução (Bell, 2008).

Foi nesse ambiente de contenda religiosa no início do século XVIII que Joseph Smith Jr. (JS), vivendo com sua família na cidade de Palmyra, Estado de Nova Iorque, iniciou suas reflexões sobre religião devido às disputas doutrinárias entre as religiōes estabelecidas na região (Bushman, 2008). Em suas próprias palavras, Smith (2019, p.53) relata:

No decorrer do segundo ano após nossa mudança para Manchester, houve, no lugar onde morávamos, um alvoroço incomum por questóes religiosas. Começou com os metodistas, mas logo se generalizou entre todas as seitas daquela parte do país. Em verdade, toda a regiấo parecia afetada por esse alvoroço e grandes multidóes uniram-se aos diferentes grupos religiosos, o que criou considerável agitação e divisão entre o povo, clamando alguns "Eis aqui!" e outros "Eis ali!" Uns contendiam pela fé metodista, outros pela presbiteriana e outros pela batista.

A efervescência religiosa desse período teve um grande impacto em JS, levando-o, após manifestações metafísicas, à fundação de a Igreja de Jesus Cristo dos Santos dos Últimos Dias (igreja).

O objetivo da investigaçáo no período entre a fundação da igreja e o assassinato de JS, seu fundador, profeta e candidato à presidência dos Estados Unidos, é descobrir as condiçóes que levaram JS a desenvolver seu pensamento político e se candidatar à presidência com o apoio da igreja, enquanto lançava as bases doutrinárias para a consolidação da igreja.

Para tanto, utilizaremos como metodologia o estudo de caso, que, junto com a técnica de process tracing, que explicaremos a seguir, bem como as condiçóes antecedentes que desencadearam todos os eventos que pretendemos investigar. 


\section{Process tracing e condiçóes antecedentes}

O process tracing é o tipo básico de investigação científica nas ciências sociais, que, junto com o estudo de caso como método específico de análise, se torna robusto analiticamente (Bennett e Checkel, 2014). As evidências por ele coletadas são as mais valiosas para "[...] refutar ideias convencionais se estiverem erradas, desenvolver novas ideias melhores e testar as novas e as antigas [...]" (Brady e Collier, 2010, p. 202, tradução nossa).

A modalidade de process tracing que utilizaremos nesta investigação será a chamada explaining outcome, que, segundo Beach e Pedersen (2013, p. 11, tradução nossa):

Terceiro, e mais comum na prática, é a situação em que queremos explicar um resultado histórico particularmente intrigante. Aqui, a ambição não é centrada na teoria de construir ou testar um mecanismo teorizado generalizável; em vez disso, o objetivo é elaborar uma explicação suficiente do resultado. Em vez de estudar mecanismos que causam guerra $(\mathrm{Y})$, a análise se concentraria em explicar um resultado específico, como a Guerra Mundial.

Desse modo, dentro dos marcadores temporais que compreendem desde a fundação da igreja ao assassinato de JS, buscaremos traçar as microcausas que normalmente se perdem na análise histórica, que, no nosso estudo de caso, extrapolará para a sedimentação do preceito fundamental da liberdade religiosa que era consagrada na Constituição Americana, mas que precisava ser colocada em teste no processo de colonização do Oeste.

Feitas as consideraçóes a respeito da técnica de pesquisa, passaremos ao exame das condiçóes antecedentes, que serão determinantes para o desencadeamento dos eventos que se investigará e abrir a "caixa preta" da causalidade (Evera, 1997; Elster, 2007).

Diante das severas disputas religiosas, conforme vimos anteriormente, Smith (2019, p. 57), em suas reflexóes acerca do tema, ao ler uma passagem na Bíblia - Tiago 1:5 - encontra a resposta às suas dúvidas sobre religião: "Em meio à inquietação extrema causada pelas controvérsias desses grupos de religiosos, li um dia na Epístola de Tiago, primeiro capítulo, versículo cinco, o seguinte: $\mathrm{E}$, se algum de vós tem falta de sabedoria, peça-a a Deus, que a todos dá liberalmente, e o não lança em rosto, e ser-lhe-á dada."

Na primavera de 1820, JS decidiu seguir o conselho encontrado no versículo bíblico, o que o levou ao primeiro evento significativo na formação da igreja. Ele retirou-se para o bosque próximo de sua residência, colocou-se de joelhos e iniciou uma oraçáo. Como resposta à sua petiçấo, Smith $(2019$, p. 58$)$ relata:

Quando a luz pousou sobre mim, vi dois Personagens cujo esplendor e glória desafiam qualquer descrição, pairando no ar, acima de mim. Um deles falou-me, chamando-me pelo nome, e disse, apontando para o outro: Este é Meu Filho Amado. Ouve-O! Meu objetivo ao dirigir-me ao Senhor era saber qual de todas as seitas estava certa, a fim de saber a qual me unir. Portanto, táo logo me controlei o suficiente para poder falar, perguntei aos Personagens que estavam na luz acima de mim qual de todas as seitas estava certa (pois até aquele momento jamais me ocorrera que todas estivessem erradas) e a qual me unir. Foi-me respondido que não me unisse a qualquer delas, pois estavam todas erradas; e o Personagem que se dirigia a mim disse que todos os seus credos eram uma abominaçáo a sua vista; que aqueles religiosos eram todos corruptos; que "eles se aproximam de mim com os lábios, mas seu coraçấo está longe de mim; ensinam como doutrina os mandamentos de homens, tendo aparência de religiosidade, mas negam o seu poder." 
O segundo grande evento que marca a formação da igreja é a tradução e publicação do "Livro de Mórmon: Um Outro Testamento de Jesus Cristo". Após um ano da chamada Primeira Visão, Smith (2019, p. 61) relata que recebeu a visitação celestial de um anjo chamado Moroni:

\begin{abstract}
Chamou-me pelo nome e disse-me que era um mensageiro enviado a mim da presença de Deus e que seu nome era Moroni; que Deus tinha uma obra a ser executada por mim; e que meu nome seria considerado bom e mau entre todas as naçóes, tribos e línguas, ou que entre todos os povos se falaria bem e mal de meu nome. Disse-me que havia um livro escondido, escrito em placas de ouro, que continha um relato dos antigos habitantes deste continente, assim como de sua origem e procedência. Disse também que o livro continha a plenitude do evangelho eterno, tal como fora entregue pelo Salvador aos antigos habitantes.
\end{abstract}

As placas continham o relato dos antigos habitantes das Américas, ancestrais dos índios e das civilizaçóes anteriores a eles que desapareceram, mas deixaram seus vestígios espalhados pelo continente. Trata-se de uma compilação histórica, de revelações proféticas, e tem como ponto culminante a visitação do próprio Jesus Cristo aos habitantes das Américas após sua ressureição. O livro compreende um período entre 600 a. C. e 421 d. C. e foi compilado pelo profeta chamado Mórmon, assim, por esta razão, os membros da igreja são conhecidos como mórmons (Bushman, 2007).

Assim, chegamos ao estabelecimento formal da igreja como instituição. Após a tradução e impressão do Livro de Mórmon, iniciou-se um período de proselitismo que trouxe consigo um número considerável de adeptos, mas, ao mesmo tempo, grande contenda com as outras religióes tradicionais estabelecidas nas colônias americanas. Segundo o Nosso Legado:

O Senhor revelou a Joseph Smith que a Igreja de Jesus Cristo nesta dispensação deveria ser organizada no dia 6 de abril de 1830 (Ver D\&C 20:1) ${ }^{1}$. Amigos e fiéis foram avisados e cerca de 56 homens e mulheres reuniram-se na casa de troncos de Peter Whitmer Sênior em Fayette, Estado de Nova York. Seis homens foram escolhidos pelo Profeta para ajudar na organização "em conformidade com as leis de nosso país, pela vontade e mandamentos de Deus". (D\&C 20:1) O Profeta escreveu: "Tendo dado início à reunião com uma oração solene ao Pai Celestial, prosseguimos, de acordo com o que nos fora ordenado anteriormente, pedindo a cooperaçâo de nossos irmãos a fim de sabermos se nos apoiavam como seus mestres nas coisas do Reino de Deus e se concordavam que organizássemos a Igreja de acordo com o mandamento recebido. A essas várias proposiçôes o consentimento foi unânime". Com o consentimento dos presentes, Joseph ordenou Oliver élder da Igreja e Oliver procedeu da mesma forma com o Profeta, como haviam sido instruídos pelo Senhor. O sacramento foi abençoado e distribuído entre os membros presentes. Os que tinham sido batizados foram confirmados e receberam o dom do Espírito Santo. O Profeta disse que "o Espírito Santo derramou-se profusamente sobre [eles] - alguns profetizavam, enquanto todos nós louvávamos a Deus e regozijávamo-nos imensamente”. Durante essa reunião, Joseph recebeu uma revelaçáo na qual o Senhor instruiu a Igreja a dar ouvidos às palavras do profeta como se viessem Dele mesmo. (Ver D\&C 21:4-6) (Saints, 1996, p. 22).

Desse modo, estabelecidas as condiçóes em que a igreja foi fundada, passaremos na parte seguinte deste trabalho à investigação sobre as causas da formação do pensamento

1 D\&C refere-se ao livro de Doutrina e Convênios: Doutrina e Convênios é uma coletânea de revelaçóes divinas e declaraçóes inspiradas, dadas para o estabelecimento e regulamentação do reino de Deus na Terra nos últimos dias. 
político de JS ao mesmo tempo em que ele recebia as revelaçôes de Deus e conduzia o proselitismo e expansão da igreja. Dado o objetivo de JS de edificar Sião na sua dimensão física, ou seja, não bastava somente edificar os centros de cultos nas regiôes em que o proselitismo era feito, mas também criar comunidades, fazendo assim com que os aspectos políticos e jurídicos já estivessem imbricados ao longo do processo, o que, para Durham (1944, p. 136, tradução nossa), "[...] o conceito mórmon, no qual seu sistema de organização em massa era visto como o verdadeiro 'governo de Deus', precede e sustenta algo único na experimentaçáo econômica e social americana."

\section{Os episódios de perseguiçáo religiosa e sua interseçáo com a política e liberdade religiosa}

A história da igreja e de seus membros é marcada por graves conflitos, o que os levou a ter "[...] experiências muito interessantes na interseção da religião com a política" (Wald e Calhoun-Brown, 2014, p. 299, tradução nossa). Desde a sua fundação em 1830, a perseguição enfrentada por JS e seus fiéis seguidores tivera o condáo de fazer com eles peregrinassem da Costa Leste para a Costa Oeste à custa de centenas de vidas e de prejuízo econômico (Linn, 2014). Para efeitos desta parte do trabalho, dividiremos essa etapa em três períodos: Colesville, Kirtland e Missouri, sendo certo que o mais significativo para nossa análise será este último período, que chamaremos de Guerra Mórmon.

\section{Colesville}

Sua doutrina é cristã e, portanto, muito próxima das outras religióes existentes, tais como: a salvação por intermédio de Jesus Cristo, a divindade da Trindade, batismo para remissáo dos pecados e crença na Bíblia como a palavra de Deus, dentre outras. No entanto, alguns pontos da doutrina promoveram uma maior fricção com as outras religiōes, tais como o batismo pelos mortos, o Livro de Mórmon como escritura sagrada, a continuidade de revelaçóes de Deus a seus representantes na Terra, dentre outras que afastaram a igreja do mainstream religioso da época.

No campo político, a intersecção da religião com os assuntos públicos tornou-se um grande problema para a igreja, embora desde a sua fundação a igreja tem sido uma defensora da Constituição (Durham, 1944). A ênfase da igreja na organização de Sião, ou seja, uma sociedade justa nos limites do território norte-americano. Com isso:

\footnotetext{
Eles desenvolveram comunidades unificadas que seguiram as revelaçôes de seu líder espiritual sobre assuntos econômicos, sociais e políticos. Seus números crescentes e sua vontade de votar como um bloco os tornaram uma ameaça política. Percebidos como hereges que não respeitavam os limites da igreja e do Estado, foram expulsos de suas casas e violentamente perseguidos em vários estados (Wald e Calhoun-Brown, 2014, pp. 299-300, tradução nossa).
}

O trabalho de proselitismo começou com a família de JS e dos familiares de Joseph Knight Jr. na cidade de Coleville, Nova Iorque. Knight, seus familiares e muitos de 
seus amigos se converteram e desejaram ser batizados. Desse modo, eles, juntamente com JS, Oliver Cowdery, David Whitmer e John Whitmer, construíram uma pequena represa próxima da casa de Knight para que eles pudessem ser batizados no domingo (Sabbath). No entanto, uma turba liderada por Cyrus McMaster, Doutor Boyington e Reverendo Shearer destruiu a represa. No dia seguinte, após o serviço religioso, os homens reconstruíram a represa e os batismos foram realizados (Jr., 2014).

A turba ficou ainda mais furiosa ao ver sua pretensão de evitar os batismos frustrada, assim, sob a direção de Cyrus, Boyington e Shearer, houve início de um processo judicial sob a acusação de desordem. Knight contratou dois advogados, James Davidson e John Reid, para defender JS, que, em razão das infundadas acusaçóes, fora libertado por ordem judicial (Bushman, 2007; Cannon e Dewey, 2005; Pratt, 2016).

O período de perseguição não se limitou aos processos judiciais forjados e a atos de destruição de propriedade pelos opositores da igreja. Uma batalha de ideias também teve início, com a publicação de diversos panfletos e editoriais no Painsville Telegraph, Evangelical Magazine, Gospel Advocate e Milennial Harbinger intitulados Delusions, Mormonism Unvailed e Manuscript Found.

\section{Kirtland}

Não obstante a grande oposição, a igreja se tornou forte em Colesville, respondendo como o primeiro ramo da igreja no Estado de Nova Iorque. Com isso, a expansão da igreja poderia prosseguir. Em setembro e outubro de 1830, quatro jovens membros da igreja foram chamados para missóes de proselitismo para pregar aos índios nas cercanias da cidade de Buffalo, NY e nos Estados de Ohio e Missouri. De acordo com o Nosso Legado: "Seu maior sucesso, porém, ocorreu junto aos colonizadores de Kirtland, Estado de Ohio, e arredores, onde 127 pessoas se converteram. Após a partida dos missionários, o número de santos em Ohio logo subiu para centenas, graças ao trabalho de proselitismo desses membros" (Saints, 1996, p. 31).

A cidade de Kirtland passou se ser de grande importância para a igreja, tendo em vista que JS em 02 de setembro de 1831 recebeu a revelaçáo de que os membros deveriam ser coligados naquela cidade como parte do mandamento de construir Siáo. Nessa oportunidade, aproximadamente 200 membros iniciaram os preparativos para a mudança em obediência ao mandamento recebido: "E para que escapeis ao poder do inimigo, e vos unais a mim como um povo digno, sem mancha nem culpa - Portanto por esta razão vos dei o mandamento de que fôsseis para o Ohio; e lá vos darei a minha lei e lá sereis investidos de poder do alto" (D\&C 38:31-32, p. 72).

Não obstante a obediência aos mandamentos, a perseguição dos membros da igreja continuava. $\mathrm{O}$ modo que mais prevaleceu nos períodos que se seguiram foram os abusos físicos que JS e os membros da igreja passaram a sofrer. Allen e Leonard (1992, p. 81, tradução nossa) descrevem um dos muitos episódios de abuso físico nos seguintes termos:

Certos moradores de Hiram, Ohio, manifestaram seus sentimentos pessoais com a ação da multidão dirigida contra o Profeta e Sidney Rigdon. Estimulada por uísque e escondida atrás de rostos enegrecidos, uma gangue de mais de duas dúzias de homens arrastou Joseph de sua cama durante a noite de 24 de março de 1832. Engolindo-o 
até a submissão, eles o despiram, arranharam a pele com as unhas, rasgaram sua pele. cabelo, depois manchou seu corpo com alcatrão e penas. Um frasco de ácido nítrico forçado contra os dentes espirrou em seu rosto; um dente da frente foi quebrado. Enquanto isso, outros membros da multidão arrastaram Rigdon pelos calcanhares de sua casa, batendo a cabeça no chão congelado, o que o deixou delirante por dias. Os amigos do Profeta passaram a noite removendo o alcatrão para ajudá-lo a manter um compromisso de pregação na manhã de domingo. Ele se dirigiu a uma congregação que incluía Simonds Ryder, organizador da multidão.

A despeito da continua perseguição, o crescimento da igreja, quantitativa e qualitativamente, incomodava muito as outras denominaçóes religiosas, que utilizavam não somente os argumentos religiosos, mas também as intersecções políticas que a igreja apresentava, para convencer autoridades governamentais de que ela representava uma ameaça à estabilidade social na cidade. Um dos grandes símbolos da prosperidade da igreja na cidade de Kirtland foi a construção do Templo, que abrigou, além de reuniões religiosas de culto, uma escola em que os membros da igreja podiam aprender idiomas e outros temas seculares que pudessem ajudá-los na expansão (Bushman, 2007; Cannon e Dewey, 2005; Givens e Grow, 2011).

No período de Kirtland, as maiores causas de perseguição de JS foram a acusação de cometer adultério com Fanny Alger, embora, segundo Bushman (2007, p. 323, tradução nossa) “[...] existe evidência de que Joseph era um polígamo em 1835 [...]”, cuja prática não se confunde com o adultério em si mesmo. Outro ponto foi a abertura e operação do Kirtland Safety Society Anti-Banking Company, que após a construção do templo teve sérios problemas financeiros, além de causas estruturais do próprio país, o que promoveram severas críticas internas a JS, o que levou vários membros a se afastarem da igreja e dar mais munição para os opositores. Neste sentido:

Na primavera de 1837, os problemas financeiros dos santos foram piorados por um pânico (mais tarde conhecido como o Pânico de 1837) que se espalhou para o oeste a partir de Nova York, por outras partes da nação. Em maio, todos os bancos de Ohio suspenderam o pagamento em espécie. Havia escassez de dinheiro durante o pânico, e muitos credores não puderam estender o crédito ou tiveram que adiar os prazos de pagamento. Joseph Smith fez todo o possível para persuadir os investidores a colocarem mais dinheiro para financiar o banco, mas teve por fim que passar a administração da companhia para outras pessoas. Isso, porém, não resolveu o problema, devido a gerenciamento incompetente e rumores de que algumas dessas pessoas estavam se apossando dos fundos da sociedade. A grande especulação que começou a ocorrer em Kirtland também contribuiu para a piora dos problemas financeiros da Igreja. Com a disponibilidade do que se supunha ser dinheiro, o qual era emprestado do banco, muitas pessoas contraíram dívidas para comprar terras a fim de vendê-las com lucro considerável. Warren Cowdery comentou no The Messenger and Advocate que não poucos membros eram "culpados de especulação desenfreada e sonhos visionários de riqueza e posses mundanas, como se o ouro e a prata fossem seus deuses, e suas casas, fazendas e mercadorias fossem sua única satisfação na vida ou a passagem para essa satisfação (System, 2003, p. 430, tradução nossa).

Todos estes eventos tiveram um impacto muito forte na igreja. Muitos membros se afastaram da igreja e passaram a perseguir os membros que se mantinham fiéis e os líderes da igreja. A situação se tornou insustentável, a tal ponto que:

Partiram finalmente de Kirtland em 6 de julho de 1838, com mais de quinhentos santos, 27 barracas, 59 carroçóes, 97 cavalos, 22 bois, 69 vacas e 1 touro. Benjamin Johnson escreveu: "Foram reunidos todos os meios disponíveis para pagar as despesas, 
por isso devíamos todos viajar juntos, enquanto estivéssemos reunidos como acampamento". Mesmo assim, os viajantes tiveram que parar de tempos em tempos para ganhar dinheiro para a compra de suprimentos e equipamentos. O Acampamento de Kirtland também sofreu perseguiçôes durante o caminho. Muitas pessoas ficaram desconfiadas dos viajantes enlameados que passavam por suas cidades e vilas. "Enquanto seguíamos pela estrada de manhã, sem molestar ninguém, alguns dos integrantes da companhia foram cumprimentados em estilo moderno, recebendo ovos jogados por baderneiros." A zombaria muitas vezes vinha combinada com ameaças (System, 2003, p. 456, tradução nossa).

\section{Missouri}

Ao mesmo tempo em que a igreja prosperava e enfrentava grandes dificuldades em Kirtland, o trabalho missionário continuou no Missouri e o sucesso em atrair conversos foi muito grande (Lesueur, 2005). Isso fez com que o condado de Jackson, Missouri, se tornasse a segunda sede da igreja, a tal ponto que a fuga de Kirtland acima descrita somente poderia ser empreendida para esta região. Em junho de 1831, JS recebeu a revelação de que Sidney Rigdon e mais 28 élderes (elders) deveriam organizar a próxima conferência da igreja em Jackson e que lá os membros receberiam sua herança e estabeleceriam Sião (D\&C, 52, p. 89).

A perseguição em Kirtland tornou-se tão severa que a única opção para JS, líderes e membros, fora considerar o exílio mais uma vez. A seção 57 de D\&C (p. 115) apresenta a revelação recebida por JS sobre a coligação dos membros da igreja em Siáo nos seguintes termos:

1 Escutai, ó élderes de minha igreja, diz o Senhor vosso Deus, vós, que de acordo com meus mandamentos vos haveis reunido nesta terra, que é a terra de Missouri, terra que designei e consagrei para a reunião dos santos. 2 Portanto, esta é a terra da promissão e o local para a cidade de Sião. 3 E assim diz o Senhor vosso Deus: Se desejais receber sabedoria, eis aqui sabedoria. Eis que o lugar que é agora chamado Independence é o lugar central; e um local para o templo se acha a oeste, num terreno não longe do tribunal. 4 Portanto, é sábio que os santos comprem a terra e também todas as áreas do oeste até a linha que passa diretamente entre judeus e gentios; $5 \mathrm{E}$ também toda a área que confina com os prados, na medida que meus discípulos puderem comprar terras. Eis que isto é sabedoria: Que eles a obtenham para herança eterna.

JS e seus seguidores seguiram a pé de Kirtland para o condado de Jackson, no Missouri, para preparar terreno para o afluxo de membros de Kirtland e de Colesville (Austin, 2012). Ele e o Bispo Partridge iniciaram, conforme D\&C 57, a adquirir lotes de terra na cidade de Kaw. A industriosidade dos membros da igreja é descrita por Emily Coburn:

Era realmente uma visão estranha ver quatro ou cinco jugos de bois subindo pelo solo rico. Cercas e outras melhorias prosseguiram em rápida sucessão. As cabanas foram construídas e preparadas para famílias o mais rápido que o tempo, o dinheiro e o trabalho pudessem realizar o trabalho (Austin, 2012, p. 67, tradução nossa).

O Missouri se localiza na fronteira com o território indígena, o que vale dizer, seus colonizadores eram na sua grande maioria pessoas sem muita educaçáo formal e buscando novas oportunidades no Oeste. $\mathrm{O}$ grande influxo de pessoas e a movimentaçáo 
no sentido de aquisição de terras, que conforme o relato acima, logo se tornou uma fonte de prosperidade, iniciando uma fonte de tensão (Spencer, 2010). Nesse ponto, a intersecção entre os temas religiosos e temporais-políticos passaram a influenciar sobremaneira o relacionamento entre os membros e não membros da igreja, pois os membros da igreja passaram a ser vistos como:

[...] Os homens orientais, cujas maneiras, hábitos, costumes e até dialeto são essencialmente diferentes dos nossos. O pior de tudo é que eles não são escravos e se opóem à escravidão; que, em um período peculiar, quando a abolição elevou sua aparência deformada e abatida em nossa terra, é bem calculada para excitar preconceitos profundos e permanentes (Bushman, 2007, p. 327, tradução nossa).

Desse modo, iniciou-se uma nova onda de perseguições contra os membros da igreja. O período em que os membros da igreja permaneceram no Missouri foi marcado por conflitos armados, que no seu conjunto são referidos como a Guerra Mórmon de 1838 (Launius, 2001). De acordo com Alexander L. Baugh:

O período do Missouri é considerado uma das épocas mais sombrias da história da Igreja dos Últimos Dias. Entre 1831 e 1839, as esperanças dos santos dos últimos dias de uma comunidade de Siáo no Condado de Jackson foram frustradas por mal-entendidos, animosidade e ação da multidão, culminando no confisco e destruição de propriedades e expulsão de cerca de 8.000 a 10.000 santos dos últimos dias. por ordem do diretor executivo do Estado (tradução nossa).

\section{A batalha de Big Blue}

Nas palavras de Spencer (2010, p. 04, tradução nossa): “[...] assentamentos industriosos estavam indo muito bem, tão bem que alguns missionários ficaram com inveja das melhorias dos colonos mórmons em suas terras". O conflito tem início quando um grupo de pessoas passa a demandar que os membros saiam da cidade e abandonem suas propriedades, pois, segundo elas, os mórmons declaravam:

[...] abertamente que seu Deus lhes deu este condado de terra, e que mais cedo ou mais tarde eles devem e terão a posse de nossas terras como herança, e em boa medida eles se comportaram em muitas ocasióes de tal maneira que acreditamos é um dever que devemos a nós mesmos, a nossas esposas e filhos, à causa da moral pública, para removê-los de nós, pois não estamos preparados para abrir mão de nossos lugares agradáveis e bens bons para eles, ou de receber no seio de nossas famílias, como companheiros aptos para nossas esposas e filhas, os negros e mulatos livres degradados e corrompidos que agora são convidados a se estabelecer entre nós. (Evening and Morning Star 2, no. 15 (December 1833), p. 114, tradução nossa).

A igreja peticiona para o governador Daniel Dunklin sobre a sistemática violação de direitos civis, resultando em uma resposta de que o tema era jurídico e não político e que ele, como governador, não poderia fazer nada. A igreja então decide processar os opositores, abrindo um processo de natureza civil no tribunal do Condado de Jackson, o que deixa os opositores ainda mais furiosos.

As agressóes se tornaram físicas com a morte de dois opositores e 1 membro, além da destruição de propriedades. O governador Dunklin decide interceder e ordena que o 
Coronel Thomas Pitcher desarme os dois lados, o que ocorreu somente em relação aos membros, dada a simpatia de Pitcher quanto à causa dos opositores (Spencer, 2010).

Assim, aproximadamente 1.200 membros ficaram indefesos, tiveram as suas propriedades destruídas e pilhadas, levando os líderes da igreja a determinar que os mesmos fugissem para o Condado de Clay, na outra margem do Rio Missouri, sendo autorizados a se estabelecer em Far West em razão da intervenção do congressista Alexander W. Doniphan (Launius, 2001).

\section{A batalha do Rio Crooked}

Após um período de relativa paz, a perseguição teve um novo momento em 1838, quando um grupo de 100 pessoas impediu os membros da igreja de votar na cidade de Gallatin, Condado de Daviess, que era um dos redutos políticos de Alexander W. Doniphan. Havia mórmons e não mórmons a crença de que os dois grupos possuíam o direito de utilizar os meios necessários para promover e defender sua cultura e valores.

O governador Lilburn W. Boggs decidiu enviar uma milícia para manter a paz, nomeando o Capitão Samuel W. Bogart, um ministro metodista simpatizante dos opositores, o que fez com que sua abordagem fosse conflituosa e os membros revidassem, sendo que quatro deles foram capturados e levados para o acampamento da milícia às margens do Rio Crooked (Jr., 2014).

Em 22 de setembro de 1838, um grupo de membros da igreja dirigiu uma petição para o governador Boggs denunciando os crimes cometidos pela milícia comandada por Bogart, o que não resultou em nenhuma ação por parte do governador.

Um batalhão mórmon de 75 pessoas foi enviado para impedir a continuidade da violência perpetrada pela milícia do Estado e resgatar os quatro prisioneiros detidos injustamente por apenas resistir ao ataque. Tiros foram trocados entre os pequenos exércitos, resultando em um pequeno número de baixas dos dois lados; no entanto, este evento deixou os mórmons em desvantagem, considerando que "[...] o resultado da batalha colocou os mórmons numa posição jurídica de ter atacado o exército do estado do Missouri” (Spencer, 2010, p. 121, tradução nossa).

Como resultado direto dessa batalha e da forte pressão da opinião pública, o governador Boggs expediu a Ordem Executiva 44, que reproduzimos integralmente:

Sede da Milícia, cidade de Jefferson, 27 de outubro de 1838.

Gen. John B. Clark:

Senhor: Desde a ordem desta manhã para você, instruindo-o a fazer com que quatrocentos homens montados sejam criados dentro de sua divisáo, recebi Amos Reese, Esq., do Condado de Ray, e Wiley C. Williams, Esq., Um das minhas ajudas, informaçôes do caráter mais terrível, que muda completamente a face das coisas, e coloca os mórmons na atitude de um desafio aberto e declarado às leis, e de terem feito guerra contra as pessoas deste Estado. Seus pedidos são, portanto, para acelerar sua operação com toda a velocidade possível. Os Mórmons devem ser tratados como inimigos e devem ser exterminados ou expulsos do Estado, se necessário para a paz pública seus ultrajes estão além de qualquer descrição. Se você pode aumentar sua força, está 
autorizado a fazê-lo na medida em que considere necessário. Acabei de emitir ordens ao major-general Willock, do condado de Marion, para criar quinhentos homens e marchá-los para a parte norte de Daviess, e ali se unir ao general Doniphan, de Clay, que recebeu ordens de quinhentos homens para prosseguir no mesmo ponto com o objetivo de interceptar a retirada dos mórmons para o norte. Eles foram orientados a se comunicar com você por expresso, você também pode se comunicar com eles, se achar necessário. Em vez disso, portanto, procedendo como inicialmente instruído a restabelecer os cidadãos de Daviess em suas casas, você seguirá imediatamente para Richmond e depois operará contra os mórmons. Brigue. O general Parks of Ray recebeu ordem de quatrocentos de sua brigada para se juntar a você em Richmond. Toda a força será colocada sob seu comando.

Muito respeitosamente [seu servo obediente],

L. W. Boggs, Comandante em Chefe. (tradução nossa)

O conflito no Rio Crooked e a Ordem Executiva 44, além da disposição dos opositores, convergiram para o massacre de Hauns Mill. As hostilidades contra os mórmons já estavam presentes pelas razóes expostas anteriormente, no entanto, uma lei que autorizava o uso da força era uma carta branca para os opositores. E não é somente isso: o texto da lei fala primeiro em extermínio e depois, como alternativa, a expulsão (Greene, 2015).

Desse modo, as condiçóes para aquilo que Alexis de Tocqueville percebeu como o clássico dilema da sociedade democrática estava posto: o exercício do poder pela maioria, ainda que em detrimento dos direitos da minoria. Ele aponta que:

Quando um homem ou um partido sofrem uma injustiça nos Estados Unidos, a quem você quer que ele se dirija? À opinião pública? É ela que constitui a maioria. Ao corpo legislativo? Ele representa a maioria e obedece-lhe cegamente. Ao poder executivo? Ele é nomeado pela maioria e lhe serve de instrumento passivo. À força pública? A força pública não passa da maioria sob as armas. Ao júri? O júri é a maioria investida do direito de pronunciar sentenças - os próprios juízes, em certos Estados, são eleitos pela maioria. Por mais iníqua e insensata que seja a medida a atingi-lo, você tem de se submeter a ela (Tocqueville, 2014, p. 296).

\section{O Massacre de Hauns Mill}

O ataque promovido pela milícia e opositores locais teve início em Hauns Mills e outras comunidades mórmons na regiáo do Hauns Creek. Muitos relatos dramáticos são feitos, basta-nos apresentar um representativo da disposição dos milicianos relatado por Nathan K. Knight:

[...] um sobrevivente do massacre alegou que os atacantes gritavam: "Mate-os, amaldiçoe-os. Mate-os. Lêndeas fazem piolhos! Segundo Knight, dois homens roubaram os mortos e chutaram alguns deles, dizendo: "Se Deus não enviou todos os mórmons para o inferno, eles deveriam pegar Jesus Cristo e servi-lo da mesma maneira" (Spencer, 2010, p. 106, tradução nossa).

Os relatos dáo conta de que aproximadamente 17 membros da igreja foram mortos e 15 gravemente feridos nesse evento. O que chama a atençáo nesse episódio é principalmente a forma com que os assassinatos foram cometidos, independente de gênero 
ou idade, pela extrema brutalidade empregada, inclusive alguns sendo queimados vivos e com tiros na cabeça depois de terem se rendido (Kinney, 2011; Gentry e Compton, 2010).

Ao tomar conhecimento do massacre, JS e os membros de outras comunidades espalhadas pela região chegaram à conclusão de que não mais poderiam manter a batalha contra a milícia estadual e decidiram render-se em $01^{\circ}$ de novembro de 1838 , o que colocou fim ao período conhecido como Guerra Mórmon (Lesueur, 1987).

Logo após o massacre, JS e outros líderes foram presos para enfrentar julgamento pelos supostos crimes cometidos. Teve início um longo período de procedimentos judiciais que Ebenezer Robinson afirmou ter sido "[...] um ato unilateral, pois as nossas testemunhas foram maltratadas e intimidadas a tal ponto que fora considerada inútil qualquer tentativa de defesa" (Bushman, 2007, p.369, tradução nossa). Ou seja, as garantias processuais mínimas não estavam presentes.

Durante o julgamento e entre as transferências entre as cadeias de Liberty e Richmond, o editor do St. Louis Republican apresentou sua percepção dos conflitos no Missouri:

\begin{abstract}
Parece, de qualquer coisa que eu tenha visto com a aparência de verdade, que os mórmons ofereceram qualquer resistência às autoridades devidamente constituídas do condado, civis e militares. Eles desejavam proteger a si mesmos, suas famílias e suas propriedades, da licenciosidade de uma multidăo e, além disso, retaliaram parte da multidão, por queimar casas e propriedades mórmons em um condado, praticando um ato semelhante. injustiça em outro (Bushman, 2007, p. 371, tradução nossa).
\end{abstract}

Foi exatamente em uma destas transferências, passados 6 meses da sua prisão, que JS e os outros prisioneiros conseguiram escapar. Eles eram considerados prisioneiros de guerra em um território hostil, a ordem de extermínio ainda estava em vigor, havia grande probabilidade que em uma das transferências entre as cadeias seus perseguidores pudessem matá-los e os procedimentos judiciais, como vimos anteriormente, tinham somente a aparência, quando em verdade náo garantiriam para os prisioneiros sequer a ampla defesa e contraditório.

\title{
O êxodo para Illinois
}

Enquanto JS estava preso, aproximadamente oito mil membros da igreja deixaram o Missouri e se dirigiram para Illinois para fugir da ordem de extermínio. Eles se refugiaram na cidade de Quincy, onde os moradores os acolheram ante sua grande aflição de lutar por suas vidas e de suas famílias, além de perderem novamente toda a sua propriedade (Bushman e Bushman, 2001; Spencer, 2010).

Com a chegada de JS, os membros se mudaram para uma região alagada aproximadamente 80 quilômetros ao Norte do Rio Mississipi. Ali os membros construíram a cidade de Nauvoo e com isso, nossa análise deve voltar-se para os aspectos políticos e jurídicos do pensamento de JS. Não que eles já não estivessem presentes desde a fundação da igreja até a chegada em Nauvoo, no entanto, é justamente neste período que suas ideias a este respeito ficam mais latentes por duas razóes: primeiro, todo histórico de perseguiçóes vividas até aquele momento e, segundo, o fato de ser uma 
nova cidade inteiramente constituída de membros da igreja (ao menos nos primeiros estágios) (Firmage, 1988).

Nauvoo passou a receber membros da igreja de partes dos Estados Unidos, Canadá e Inglaterra, tornando-se, em quatro anos, a maior cidade do Estado de Illinois (Bushman e Bushman, 2001).

\section{O pensamento político e jurídico de Joseph Smith Jr.: a construção de Siáo em Navoo}

Nesta parte do trabalho, apresentaremos as bases do pensamento político de JS que foi se consolidando ao longo do seu trajeto como presidente e profeta da igreja. As experiências que ele e seu povo vivenciaram, especialmente em Kirtland e Missouri, na construção de uma comunidade a partir de valores religiosos, mostrou-se uma fonte de grandes conflitos, conforme evidenciado na exposição das condiçóes de fundo na parte anterior do trabalho.

A mudança e construção para Nauvoo não apagaram as marcas deixadas pelas perseguiçóes, a tal ponto que o próprio JS, entre 1839 e 1840, passou boa parte do tempo em Washington peticionando para o Governo Federal no sentido de denunciar os eventos ocorridos no Missouri e recuperar as perdas financeiras. Além disso, ele precisava do Congresso para que Nauvoo fosse legalmente reconhecida como uma cidade autônoma do Estado de Illinois (Bushman, 2007).

Assim, em 1833 já podemos encontrar as primeiras evidências sobre a formaçáo do pensamento político e jurídico de JS. Nessa oportunidade, ele estava em Kirtland e recebera notícias de perseguiçóes perpetradas contra os membros da igreja no Condado de Jackson, Missouri. Ao inquirir Deus sobre a situação, recebeu a revelaçáo que se encontra em D\&C 98 (p. 216), em parte reproduzida abaixo:

\footnotetext{
$4 \mathrm{E}$ agora, em verdade vos digo com respeito às leis do país: É a minha vontade que o meu povo procure fazer todas as coisas que eu lhe mandar. $5 \mathrm{E}$ a lei do país, que for constitucional, que apoiar o princípio da liberdade na observância de direitos e privilégios, pertencerá a toda a humanidade e será justificável perante mim. 6 Portanto, eu, o Senhor, vos justifico, vós e vossos irmãos de minha igreja, no apoio à lei que é a lei constitucional do país; $7 \mathrm{E}$ quanto às leis dos homens, o que for mais ou menos do que isso provém do mal. $8 \mathrm{Eu}$, o Senhor Deus, liberto-vos; portanto, sois verdadeiramente livres. E a lei também vos liberta. 9 Mas quando os iníquos governam, o povo pranteia. 10 Deve-se, portanto, procurar diligentemente homens honestos e homens sábios; e homens bons e homens sábios devereis apoiar; pois o que for menos do que isto provém do mal ... 16 Portanto, renunciai à guerra e proclamai a paz; e procurai diligentemente voltar o coração dos filhos para os seus pais e o coraçấo dos pais para os filhos.
}

A utilização dessa linguagem nos remete àquilo que Jr. (2016) assevera, no sentido de que o direito natural pode ser acessado por revelação e por razão, o que claramente, nesse caso, refere-se à revelação. Nesse sentido, ele reproduz o pensamento de Samuel Pufendorf, segundo o qual o paradigma do direito natural tem o "[...] seu fundamento na vontade divina que, originariamente, fixou os princípios da razão humana perpetuamente" (Jr., 2016, p. 62). 
Sob o ponto do direito positivo, a linguagem nos atos e documentos na época nos remete ao reconhecimento do direito natural. Por exemplo, Boyack (2012) reforça esse argumento ao reproduzir os dois primeiros artigos da Declaração do Congresso de Massachusetts de 29 de outubro de 1765, em reaçáo do Stamp Act promulgado pela Inglaterra:

1. Resolveu-se que existem certos direitos essenciais da Constituição britânica de governo, fundados na Lei de Deus e da Natureza, e são direitos comuns da humanidade - Portanto,

2. Resolveu-se que os habitantes desta província têm direito inalienável a esses direitos essenciais em comum a todos os homens e que nenhuma lei da sociedade pode, consistente com a lei de Deus e da natureza, despojá-los desses direitos (Boyack, 2011, p.39, tradução nossa).

Ou seja, trata-se da máxima consagrada desde Aristóteles da lex injusta non est lex, que, de acordo com Adams et al. (1990, p. 08, tradução nossa), no caso da Constituição Americana:
As ideias que moldaram as atitudes coloniais às vésperas da Revolução incluem a supremacia da lei natural, o conceito de direitos inalienáveis, a importância de uma constituição escrita e o governo por consentimento popular. A Declaração da Independência incorporou amplamente essas visōes, atraindo fortemente na teoria jurídica inglesa, na tradição política Whig e na teologia da aliança puritana. Embora não tenha abordado explicitamente a questão da liberdade religiosa, a Declaração se apoiava em pressupostos amplamente teístas e continha quatro referências à Deidade: "Deus da Natureza" e "Criador" nos dois primeiros parágrafos e "Juiz Supremo do Mundo" e "Providência Divina" no parágrafo final. As palavras mais famosas do do- cumento divulgam sua premissa teísta: "Consideramos essas verdades autoevidentes, que todos os homens são criados iguais, que são dotados por seu Criador de certos bens inalienáveis. Direitos, entre os quais à Vida, à Liberdade e à busca da felicidade.

No entanto, no caso dos mórmons, não é o caso da oposição entre o direito positivo e o direito natural (exceto é claro no caso da Ordem Executiva 44, que determinou o extermínio e expulsão dos mórmons no Missouri), mas a construção e consolidação dos limites de proteção dos direitos e garantias como previstos na Constituição NorteAmericana vis a vis os limites de poderes no quadro político do federalismo.

A Primeira Emenda possui 2 clausulas referentes à liberdade religiosa: o direito de livre exercício e a proibição de que qualquer lei regule o estabelecimento de religião. Por outro lado, a questão do federalismo é anterior mesmo à própria Constituição, que não seria aprovada sem o consentimento da manutenção dos poderes já adquiridos pelas Colônias quando da independência. De acordo com Burnham (2011, p. 18, tradução nossa), em relação aos Estados quando da adoção da Constituição: "Não havia necessidade de criá-los porque eles já existiam em 1787. De fato, os Estados escreveram e ratificaram suas próprias constituições rapidamente - todas as possuíam no final de 1776".

A harmonização de conflitos entre cláusulas constitucionais, especialmente no que diz respeito à liberdade religiosa e o exercício de poder dos Estados, fora um processo lento e que, no caso do Missouri e de outros Estados que estavam na fronteira com o território indígena, um processo marcado pela violência, como evidenciado acima, o que não exclui em certo grau a ocorrência de atos de intolerância mesmo no Estado de Nova Iorque, onde a pluralidade de igrejas e seitas era grande (Schwartz, 1995). 
Não avançaremos em uma descrição detalhada de como a harmonização foi desenvolvida e construída, pois, como verificamos da exposição das condiçóes em que os eventos de desenrolaram, havia uma discrepância não somente jurídica, mas também cultural entre os Estados. Tomando em consideração o marco inicial de nossa investigação, que é a fundação da igreja, pode-se afirmar com elevado grau de certeza que o pensamento político e legal de JS possuem traços que coincidem com os adotados pelos Fundadores. Fatores como a pluralidade de religióes na regiáo em que passou boa parte de sua infância e adolescência e as perseguiçóes em grau crescente ao se mover do Leste para o Oeste construíram as bases de seu pensamento.

Em 17 de agosto de 1835, a Assembleia Geral da igreja adotou a Declaraçáo de crença relativa aos governos e leis em geral, que foi introduzida no Livro dos Mandamentos como D\&C 134 (pp. 321-2), em cujos versículos 1 e 2 lê-se:

1 Nós cremos que os governos foram instituídos por Deus em benefício do homem; e que ele considera os homens responsáveis por seus atos em relação aos mesmos, tanto na formulação de leis como em sua execução, para o bem e segurança da sociedade. 2 Cremos que nenhum governo pode existir em paz a não ser que tais leis sejam feitas e mantidas invioladas, de modo a garantir a todo indivíduo o livre exercício de consciência, o direito e domínio de propriedade e a proteção da vida.

Naturalmente, a declaração refere-se à experiência de governo que a igreja possuía naquela oportunidade, o que excluiria formas de governo totalitárias, não obstante ter ficado clara que a responsabilidade pessoal do governante e a prevalência de uma lei superior sem começo ou fim de dias, eterna (Sófocles, 2015). Fica claro também os principais direitos e garantias para a igreja: vida, propriedade e expressão.

No documento Political Motto, escrito em março de 1838 por JS, fica claro que as afirmaçóes em D\&C 134 ao se referir à lei estão alicerçadas na Constituição dos Estados Unidos como uma lei suprema que possa dar conta adequadamente dos conflitos que o federalismo e a soberania dos Estados pudessem trazer para os cidadãos:
A Constituição do nosso país, formada pelos Padres da Liberdade. Paz e boa ordem na sociedade Amor a Deus e boa vontade ao homem. Todas as leis boas e saudáveis; E virtude e verdade acima de todas as coisas e aristarquia vivem para sempre!!! Mas ai de tiranos, turbas, aristocracia, anarquia e tóris [tories]: E todos aqueles que inventam ou buscam açôes judiciais injustas e vexatórias sob o pretexto ou a cor da lei ou cargo, seja religioso ou político. Exalte o padrão da democracia! Abaixo o do Sacerdócio, e que todas as pessoas digam Amém! para que o sangue de nossos pais náo chore da terra contra nós. Sagrado é a memória desse sangue que comprou para nós nossa liberdade. (Smith, 1964, p. 191, tradução nossa).

JS, ao mesmo tempo que exulta a Constituição baseada nas leis de Deus e na fraternidade com os homens (pode-se dizer que ele coloca a necessidade do cumprimento dos dois grandes mandamentos - amar a Deus e o semelhante como a si mesmo), o que ele já havia revelado em D\&C 98, condena formas de governo e práticas não democráticas; reprova as perseguiçóes políticas e pseudolegais baseadas em crenças religiosas e coloca como sagrado o sangue daqueles que morreram para garantir a liberdade.

Pode-se afirmar com segurança que as visóes de JS sobre a política e a lei são compartilhadas por membros e não membros, porque fazem parte do paradigma do direito natural e, no caso da Constituição, do próprio direito positivo; no entanto, o contexto 
social, cultural e religioso fez com que a interpretação dos mesmos apresentasse significados conflitantes na sua grande maioria. Para Durham (1944), os temas de natureza religiosa para a igreja, como a ordem unida, casamento plural, estabelecimento de Siáo na terra e outros pontos específicos da doutrina da igreja poderiam estar acobertados pela Constituição. No entanto, nessa época de construção de consensos e reconciliação para o país, as ideias e doutrinas apresentadas certamente não se encaixavam muito bem na sociedade, causando uma esperada fricção.

Ainda no Political Motto fica claro que, no que tange à fé cristã, uma coisa é perdoar aqueles que nos ofendem na dimensão pessoal, e outra é a obrigação de buscar a justiça em relação aos atos perpetrados no Missouri na dimensão coletiva.

Por essa razão, no final de 1839, JS, Sidney Rigdon, Juiz Elias Higbee e Orrin Porter Rockwell viajaram para Washington D.C. para apresentar um relato dos fatos para o Congresso. Enquanto, em Washington, JS e Elias Higbee foram recebidos pelo Presidente Martin Van Buren, que, de acordo com Jr. (2014, v. 4, p. 09, tradução nossa), "[...] sentiu simpatia pelos Mórmons quanto aos seus sofrimentos."

JS e Higbee permaneceram em Washington por dois meses buscando o apoio de senadores e congressistas para a sua causa. Em fevereiro de 1840, eles foram recebidos novamente pelo Presidente Van Buren, que, de acordo com JS, os tratou rudemente e declarou: "Senhores, sua causa é justa mas eu não possa fazer nada por vocês...se eu ficar ao seu lado perderei os votos do Missouri” (Jr, 2014, v.4, p.40, tradução nossa). Depois de todo sofrimento, mortes e perdas financeiras, a esperança de JS e dos líderes da igreja, especialmente considerando sua postura ante a Constituição, foi destroçada, pois até o Presidente dos Estados Unidos lhes dava as costas.

Com a proximidade das eleiçóes em 1844, JS publicou um editorial no Times and Seasons, cidade de Nauvoo, em $01^{\circ}$ de outubro de 1843 (p. 343). Nele, traz um relato sobre o tempo que dispendeu em Washington e a decepção que sofrera, pois, segundo ele, para pessoas de fino trato vivendo em uma sociedade civilizada era muito difícil imaginar que tais atos pudessem ser praticados sob os auspícios de um governo republicano. Nesse mesmo editorial ele fez a seguinte pergunta: quem será o nosso próximo presidente? Ele não sugeriu ou apoiou nenhum nome, mas disse que deveria ser um que apoiasse a igreja na busca por justiça no Missouri.

No dia 04 de novembro de 1843, JS escreveu cartas para os candidatos até aquele momento ${ }^{2}$ relatando o ocorrido no Missouri e a seguinte pergunta: "Qual será a sua decisão relativa a nós como pessoas, foi a sorte a seu favor ao ascender à magistratura?" (Jr., 2014, v. 6, p. 65, tradução nossa). Segundo Arnold K. Garr: "Somente Calhoun, Cass, e Clay responderam as cartas de Joseph Smith, expressando pouca simpatia pela causa dos santos" (tradução nossa). A resposta de JS para Calhoun foi enfática:

Permita-me, como homem respeitador da lei, como adepto da perpetuidade dos direitos e liberdade constitucionais e como amigo da adoração livre de Deus Todo-Poderoso por todos, de acordo com os ditames da consciência de cada pessoa, para dizer Estou surpreso que um homem ou homens nas estações mais altas da vida pública devam

2 Para uma relação completa dos candidatos, ver: DUBIN, M. J. United States Presidential Elections, 1788-1860: The Official Results by County and State. Reprint edition ed. Jefferson, N.C.: McFarland, 2011. 
ter inventado uma "visão" tão frágil de um caso. Um "Estado soberano" é muito mais poderoso do que os Estados Unidos, o governo pai, que pode exilá-lo por prazer, conspirar impunemente, confiscar suas terras e propriedades, fazer com que o Legislativo o sancione - sim, até assassiná-lo como um édito de um imperador, e não faz mal; para o nobre senador da Carolina do Sul, diz que o poder do governo federal é tão limitado e específico que não tem jurisdição sobre o caso! $\mathrm{O}$ que você acha do imperium in imperio? (tradução nossa).

Quando JS percebeu que nenhum dos candidatos daria qualquer apoio à sua causa e que alguns dos residentes do Missouri ainda permaneciam firmes em não deixar a igreja e seus membros em paz, convocou uma reuniáo com os doze apóstolos na prefeitura de Nauvoo no dia 29 de janeiro de 1844, na qual, por unanimidade, ficou decidido que JS concorreria para a presidência dos Estados Unidos de forma independente:

Diga às pessoas que tivemos Whig e presidentes democratas por tempo suficiente; queremos um presidente dos Estados Unidos. Se algum dia eu assumir a presidência, protegerei o povo em seus direitos e liberdades. Nâo vou ser eleito por mim mesmo. Há oratório suficiente na Igreja para me levar à cadeira presidencial na primeira votação (Jr., 2014, v. 6, p. 188, tradução nossa).

A plataforma presidencial de JS foi publicada em 1844 sob o nome de General Smith's Views of the Powers and Policy of the Government of the United States. Nela, ele apresentava os temas importantes para a época, sem, contudo, apresentar diretamente os incidentes do Missouri (Jr., 2016). Sua principal proposta estava justamente associada à autonomia dos Estados em relação à União, que, segundo JS:

Dê a todos os homens sua liberdade constitucional e o presidente plenos poderes para enviar um exército para suprimir multidóes; e a autoridade dos Estados para revogar e impugnar essa relíquia da loucura, o que torna necessário que o governador de um Estado faça a demanda do presidente por tropas, em caso de invasão ou rebelião (Jr., 2016, p. 01, tradução nossa).

A proposta de intervenção da União sobre assuntos dos Estados foi claramente uma resposta aos eventos trágicos de Missouri. Ocorre que essa proposta náo considerou o posicionamento contrário da Suprema Corte dos Estados Unidos no caso Barron v. Mayor \& City Council of Baltimore (32 U.S. 243 - 1882). A corte se posicionou no sentido de que: "A Constituição foi ordenada e estabelecida pelo povo dos Estados Unidos para ele mesmo, para o seu governo e não para os governos individuais dos Estados" (tradução nossa). É nesse sentido que Boyack (2011, p. 21, tradução nossa) esclarece:

Isso é para ser acreditado? Se os governos estaduais decidissem negar a qualquer grupo de pessoas os direitos básicos da Primeira Emenda, eles poderiam fazê-lo? Infelizmente sim. Esse é o pequeno segredo sujo da América do século XIX. Essa grande Declaração de Direitos pertencia apenas ao governo federal. Em outras palavras, apenas o governo federal teve que respeitar esses direitos preciosos. Os Estados poderiam fazer o que quisessem. Eles poderiam aplicar esses direitos sagrados ou negá-los. Muitas vezes, eles escolheram o último. E o governo federal, concordando com a interpretação constitucional dos Estados, não viria em socorro. Como resultado, os santos dos últimos dias e outras minorias sofreram muito.

Ainda que não se tenham evidências, pode-se inferir que esse precedente legal de 1822 tenha influenciado JS e o Juiz Higbee a não procurarem a Suprema Corte em 
1839, durante a sua permanência de 2 meses em Washington, mas tão somente os representantes do Executivo e Legislativo.

A abolição da escravidão integrou sua plataforma. Sua proposta compreendia não somente a libertação dos escravos, mas também a compensação para os proprietários dos escravos que seria paga com a venda de terras públicas e com o que fosse economizado com a redução do tamanho do Congresso e dos salários pagos para os congressistas (Jr., 2016). Nesse sentido, ele promove a ideia da existência de uma verdade autoevidente de que todos os homens foram criados igualmente e, portanto:

[...] que eles são dotados pelo seu Criador de certos direitos inalienáveis; que entre eles estão a vida, a liberdade e a busca da felicidade, mas ao mesmo tempo cerca de dois ou três milhóes de pessoas são consideradas escravas da vida, porque o espírito nelas é coberto por uma pele mais escura que a nossa (Jr., 2016, p. 02, tradução nossa).

Uma reforma penal deveria ser promovida com a eliminação da prisão por dívidas e cortes marciais por deserção, fazendo com que o sistema carcerário pudesse ser mais humano e reformador de caráter espiritual. A formação de um banco nacional, a anexação do Texas e Oregon e a expansão do território dos Estados Unidos para além da fronteira indígena, conquanto os seus habitantes - os índios - concordassem, completavam a plataforma política da JS (Balmer e Riess, 2015).

As propostas de JS, como vimos, em boa parte refletia o contexto político e jurídico que o país estava vivendo, além de incorporar os aspectos vivenciados especificamente pelos membros da igreja, que, para JS, não deveriam ser esquecidos e a que todos deveriam ter o direito. Nesse sentido, ele justifica a sua candidatura:

Eu não aceitaria que meu nome tivesse sido usado por meus amigos como Presidente dos Estados Unidos ou candidato a esse cargo, se eu e meus amigos pudéssemos ter o privilégio de desfrutar de nossos direitos civis e religiosos como cidadãos americanos, mesmo os direitos que a Constituição garante a todos os seus cidadãos. Mas isso como um povo nos foi negado desde o início. De tempos em tempos, perseguiçóes rolavam sobre nossas cabeças, de partes dos Estados Unidos, como trovóes, por causa de nossa religiāo; e ainda nenhuma parte do governo avançou em nosso socorro. E, em vista dessas coisas, sinto que é meu direito e privilégio obter a influência e poder que posso, legalmente, nos Estados Unidos, para proteger a inocência ferida (Jr, 2014, v. 6, pp. 210-211, traduçáo nossa).

Não se pode testar como a candidatura e as propostas de JS foram recebidas fora do círculo dos membros da igreja como uma alternativa às plataformas dos partidos Republicano, Democrata e Whig em razáo do seu assassinato em 27 de junho de 1844 na cidade de Carthage, Illinois. A respeito do ocorrido, o governador de Illinois declarou:

O assassinato dos Smiths, em vez de pôr um fim [...] aos mórmons e dispersá-los, como muitos acreditavam que aconteceria, apenas uniu-os mais do que nunca, dando-lhes nova confiança em sua fé. Algum homem talentoso como Paulo, algum esplêndido orador, capaz de, com sua eloquência, atrair multidóes de pessoas [...] pode ter sucesso em dar nova vida à [igreja mórmon] e fazer o nome do mártir Joseph ressoar [...] alto e tocar a alma dos homens (Saints, 1996, p. 14, tradução nossa).

Embora não faça parte dos limites desta investigação, é necessário acrescentar que a morte de JS não arrefeceu o ímpeto dos seus seguidores, como pensavam seus opositores. 
Brigham Young sucedeu JS como presidente e profeta da igreja. Em 06 de abril de 1845, emitiu o documento Proclamation of the Twelve Apostles of the Church of Jesus Christ of Latter-day Saints to all The Kings of the World, To the President of the United States of America; To the Governors of the Several States, And to the Rulers and Peoples of all Nations, em que deixava claro que a obra iniciada por JS continuaria:

[...] à medida que esse trabalho progride em seu curso progressivo, e se torna cada vez mais um objeto de interesse e excitação política e religiosa, nenhum rei, governante ou sujeito - nenhuma comunidade ou indivíduo permanecerá neutro: todos finalmente tomarão partido a favor ou contra o Reino de Deus ... Portanto, você não pode permanecer como espectador ocioso e desinteressado das cenas e eventos que são calculados, em sua própria natureza, para reduzir todas as naçóes e credos a um padrão político e religioso, e assim colocar um fim às formas e nomes de Babel e à luta e guerra. Portanto, você será guiado pelo bom Espírito a lançar-se em sua sorte e a ter um vivo interesse com os santos do Altíssimo e com o povo da aliança do Senhor; ou, por outro lado, você se tornará seu inimigo inveterado e se oporá a eles por todos os meios ao seu alcance (Durham, 1944, p. 141, tradução nossa).

No final do ano de 1845, devido às graves perseguiçôes, Brigham Young e os muitos líderes e membros decidiram partir de Nauvoo para a regiāo das Montanhas Rochosas, onde atualmente está localizada a cidade de Salt Lake. A peregrinação dos membros de Nauvoo e o sucesso dos missionários da igreja na Europa promoveram a chegada na região de um grande contingente de pessoas até o ponto em que o Estado de Utah foi criado (Saints, 1996). A abordagem de Brigham Young pareceu seguir a de JS:

Somos um povo político? Sim, muito político. Mas a que partido vocês pertencem ou em quem votariam? Eu lhes direi em quem votaremos: votaremos no homem que apoie os princípios de liberdade civil e religiosa, no que tiver maior conhecimento e que tiver o melhor coração e cérebro para ser um estadista. Pouco nos importa se ele é um liberal-conservador, um democrata, [...] um republicano, [...] ou qualquer outra coisa. Essa é nossa política.

\section{Conclusão}

Alex Beam, em seu livro American Crucifixion: The Murder of Joseph Smith and the Fate of the Mormon Church, dentre outros autores, aponta para a grande contribuição que a comunidade mórmon deu para a formação cultural, política e jurídica dos Estados Unidos. Os conflitos entre os valores que fazem parte da doutrina da igreja e aqueles advogados pelos não membros até hoje podem ser sentidos. Tome-se por exemplo a firme posição da igreja contra a uniáo entre pessoas do mesmo sexo. No entanto, com a consolidação de um estado de direito, tais disputas são resolvidas, em última análise, pela Suprema Corte.

Como verificamos na análise, nem sempre fora assim. Encontramos a discrepância que existia na percepçáo de liberdade religiosa entre os Estados do Leste e aqueles mais a Oeste, na fronteira com o território indígena. A consolidação dos limites desse direito fundamental e os limites do poder dos Estados federados e o poder da Uniáo sobre eles estavam sendo construídos.

Os novos valores apresentados por JS entravam em choque direto com aqueles da sociedade naquele período, a tal ponto que podemos observar um acirramento das 
perseguiçóes aos membros da igreja na medida em que se movem de Leste para Oeste, ou seja, de uma sociedade mais aberta para uma mais fechada. Colesville, Kirtland e Missouri comprovam empiricamente essa proposição e se colocam como os três lugares em que estes eventos tiveram um papel essencial no desenvolvimento do pensamento político de JS. Desse modo, o process tracing revelou os eventos mais importantes e que tiveram implicaçóes causais diretas na formação do pensamento político de JS, conforme resumidos abaixo:

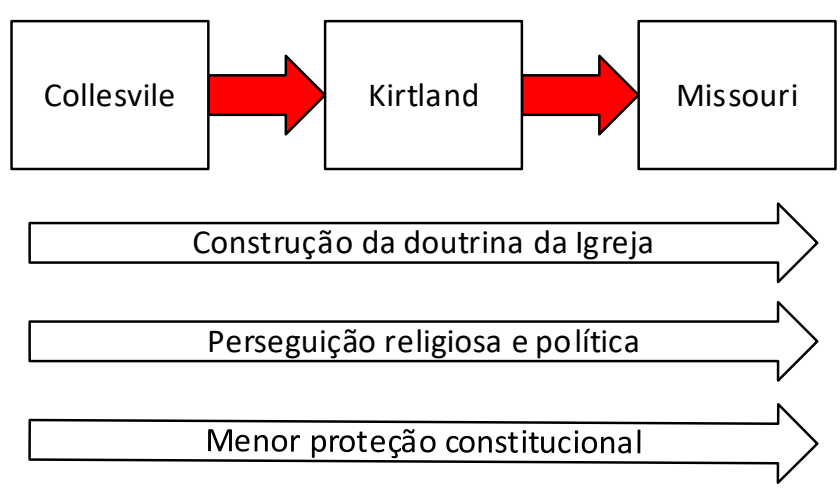

Fonte: Elaboração do autor (2020).

O pensamento político foi consolidado com a sua candidatura a presidente dos Estados Unidos apresentando elementos iluministas de caráter universal, que, da mesma forma, eram menos aceitos de Leste para Oeste, causando, assim, mais atrito entre as comunidades envolvidas.

Concluímos que as evidências coletadas e analisadas atestam para a necessidade que JS teve de, ao mesmo tempo em que construía a igreja juntamente com seus seguidores, desenvolver a estratégia política e jurídica para enfrentar os desafios reportados neste trabalho. Os materiais analisados nos permitem afirmar que suas convicçóes foram moldadas pelos eventos espirituais e históricos vivenciados desde a Primeira Visáo até a sua morte. Estavam certas? As evidências encontradas apontam, ainda que não se possa atribuir uma relação direta entre as suas ideias os acontecimentos posteriores à sua morte, para acertos como no caso da Guerra Civil, que ele já havia previsto, e a promulgação das emendas constitucionais 13 (proibição da escravidão) e 14 (proibição de os Estados restringirem os direitos constitucionais). Examinando o relatório estatístico da igreja de 2020, sob as dimensóes religiosa e política, parece que sim.

\section{Referências}

ADAMS, A. M.; EMMERICH, C. J.; BURGER, W. E. A nation dedicated to religious liberty: the constitutional heritage of the religion clauses. Philadelphia: University of Pennsylvania, 1990.

ALLEN, J. B.; LEONARD, G. M. The Story of the Latter-Day Saints. 2 Rev Enl edition ed. Salt Lake City, Utah: Deseret Book Co, 1992.

AUSTIN, E. M. Mormonism, or life among the mormons. RareBooksClub.com, 2012. 
O legado político de Joseph Smith Jr., o fundador da igreja Mórmon

BALMER, R.; RIESS, J. (ORGS.). Mormonism and American Politics. New York: Columbia University, 2015.

BEACH, D.; PEDERSEN, R. B. Process-Tracing Methods: Foundations and Guidelines. Ann Arbor: University of Michigan, 2013.

BEAM, A. American Crucifixion: The Murder of Joseph Smith and the Fate of the Mormon Church. First Edition edition ed. New York: Public Affairs, 2014.

BELL, J. B. A War of Religion: Dissenters, Anglicans and the American Revolution. Houndmills, Basingstoke, Hampshire; New York: Palgrave Macmillan, 2008.

BENNETT, A.; CHECKEL, J. T. (ORGS.). Process Tracing: From Metaphor to Analytic Tool. Cambridge; New York: Cambridge University, 2014.

BICKNELL, J. America 1844: religious fervor, westward expansion, and the presidential election that transformed the nation. Chicago, Illinois: Chicago Review, 2014.

BOYACK, C. Latter-day Liberty: A Gospel Approach to Government and Politics. 1St Edition edition ed. Springville, Utah: Cedar Fort, Inc., 2011.

BRADY, H. E.; COLLIER, D. (ORGS.). Rethinking Social Inquiry: Diverse Tools, Shared Standards. 2 ed. Lanham, Md: Rowman \& Littlefield, 2010.

BURNHAM, W. Introduction to the Law and Legal System of the United States. 5 ed. St. Paul, MN: West Academic, 2011.

BUSHMAN, C. L.; BUSHMAN, R. L. Building the Kingdom: A History of Mormons in America. New York: Oxford University Press, 2001.

BUSHMAN, R. L. Joseph Smith: Rough Stone Rolling. Reprint edition ed. New York: Vintage, 2007.

BUSHMAN, R. L. Mormonism: A Very Short Introduction. New York: Oxford University, 2008.

CANNON, G. Q.; DEWEY, R. L. Life of Joseph Smith the Prophet, UNABRIDGED. Provo, Utah: Stratford Books, 2005.

DUBIN, M. J. United States Presidential Elections, 1788-1860: The Official Results by County and State. Jefferson: McFarland, 2011.

DURHAM, G. H. A Political Interpretation of Mormon History. Pacific Historical Review, v. 13, n. 2, pp. 136-150. doi: 10.2307/3634609, 1944.

EVERA, S. V. Guide to Methods for Students of Political Science. 1 edition ed. Ithaca: Cornell University Press, 1997.

FIRMAGE, E. B.; MANGRUM, R. C. Zion in the courts: a legal history of the Church of Jesus Christ of Latter-day Saints, 1830-1900. Urbana: University of Illinois, 1988. 
GENTRY, L. H.; COMPTON, T. M. Fire and Sword: A History of the Latter-Day Saints in Northern Missouri, 1836-39. Salt Lake City, Utah: Greg Kofford, 2010.

GIVENS, T. L.; GROW, M. J. Parley P. Pratt: The Apostle Paul of Mormonism. 1 edition ed. Oxford; New York ; Auckland ; Cape Town ; Dar es Salaam ; Hong Kong ; Karachi ; Kuala Lumpur ; Madrid ; Melbourne ; Mexico City ; Nairobi ; New Delhi ; Shanghai ; Taipei ; Toronto: Oxford University Press, 2011.

GREENE, J. P. Facts Relative to the Expulsion of the Mormons or Latter-Day Saints, From the State of Missouri, Under the Exterminating Order by John P. Greene, an ... of the Mormons. Forgotten Books, 2015.

JR., J. S. The History of the Church - All Seven Volumes - The Complete LatterDay Saint Reference (B. H. Roberts, Org.). 4th eBook ed. Chickadee LLC, 2014.

JR., S. J. General Smith's Views of the Powers and Policy of the Government of the United States. Hardpress Publishing, 2016.

JR., T. S. F. Introdução ao Estudo do Direito. Método, 2016.

KINNEY, B. G. The Mormon War: Zion and the Missouri Extermination Order of 1838. 1st Edition ed. Yardley, Pa: Westholme Publishing, 2011.

LAUNIUS, R. D. Review of A History of the Latter-day Saints in Northern Missouri; from 1836 to 1839; A Call to Arms: The 1838 Mormon Defense of Northern Missouri. The John Whitmer Historical Association Journal, v. 21, pp. 109-111.

LESUEUR, S. C. Missouri's Failed Compromise: The Creation of Caldwell County for the Mormons. Journal of Mormon History, v. 31, n. 2, pp. 113-144, 2005.

LESUEUR, S. C. The 1838 Mormon War in Missouri. Columbia: University of Missouri, 1987.

LINN, W. A. The Story of the Mormons From the Date of Their Origin to the Year 1901. Create Space Independent Publishing Platform, 2014.

POLL, R.; ALEXANDER, T. G.; CAMPBELL, E. E.; MILLER, D. E. (ORGS.). Utah's History. 1 edition ed. Logan, Utah: Utah State University Press, 1989.

PRATT, P. P. A Voice of Warning. Create Space Independent, 2016.

ROBERTS, B. H. A Comprehensive History of the Church of Jesus Christ of Latter-day Saints: Century One. Kofford Classics, 2012.

SAINTS, T. C. Our Heritage, A Brief History of The Church of Jesus Christ of Latter-Day Saints. The Church of Jesus Christ of Latter-day Saints, 1996.

SCHWARTZ, B. A History of the Supreme Court. Revised ed. edition ed. New York: Oxford University Press, 1995. 
SMITH, J. Political Motto. BYU Studies Quarterly, v. 5, n. 3, 1 out. 1964.

SÓFOCLES. Antígona. PENGUIN CLÁSSICOS, 2015.

SPENCER, T. M. (ORG.). The Missouri Mormon Experience. 1 edition ed.

Columbia, Mo: University of Missouri, 2010.

SYSTEM, C. E. Church History in the Fulness of Times, Student Manual. 2nd edition ed. [s.l.] The Church of Jesus Christ of Latter-day Saints, 2003.

TOCQUEVILLE, A. DE. A Democracia na América. Leis e Costumes - Livro I. Martins Fontes - Selo Martins, 2014.

WALD, K. D.; CALHOUN-BROWN, A. Religion and Politics in the United States. 7 edition ed. Lanham: Rowman \& Littlefield, 2014.

WICKS, R. S.; FOISTER, F. R. Junius And Joseph: Presidential Politics and the Assassination of the First Mormon Prophet. 1 edition ed. Logan, Utah: Utah State University, 2005.

Recebido: 13 de fevereiro de 2019.

Aprovado: 13 de maio de 2020. 